\title{
Identity and Learning of Mathematics for Adult First Nations Students
}

\author{
Tracy Jill Shields \\ Correspondence: Tracy Jill Shields, Lakehead University, Canada \\ Received: August 30, 2013 \\ Accepted: September 18, 2013 Online Published: October 21, 2013 \\ doi:10.11114/jets.v2i1.213 \\ URL: http://dx.doi.org/10.11114/jets.v2i1.213
}

\begin{abstract}
The main goals of this article are twofold. The first is to explore whether the General Education Development (GED) program has the potential to meet the academic requirements cited by the scholarship in the area of mathematics for First Nations upgrading programs. Secondly, this paper explores how the GED program influences identity in students who are several years behind mainstream mathematics programs and who are interested in securing their high school credential equivalencies. Research was carried out in one First Nations community through a study of 11 adult students working toward the writing of their GED mathematics examination. Ethnography was justified as a methodology as it allows all aspects of Indigenous Methodology requirements within its framework. The study used interviews relevant to the early life experiences of the participants and observations and artifacts throughout the GED program itself.
\end{abstract}

Keywords: identity, First Nations, Aboriginal, mathematics, GED, adult

\section{Introduction}

This paper considers whether the academic requirements made explicit by Indigenous researchers and First Nations educators in particular, are served by the General Education Delivery (GED) program. The research seeks to determine how the GED program impacts the identity of the students it serves in the process. Upper elementary Aboriginal students lag behind mainstream students by about $20 \%$ on their numeracy performances according to data presented at the First Nations Math Education (2009) workshop. Research shows that by Grade 10 , the achievement gap tends to be larger, with only $47 \%$ of First Nations students meeting provincial government mandated standards in numeracy compared to $77 \%$ of mainstream students (Fraser, 2010).

Data from a study that took place on a remote First Nations community was analyzed while I was tutoring the students toward their GED mathematics examination. This article examines the scholarship on identity and the links between identity and the participants' desire for high school equivalency accreditation. It probes the various factors that influenced student identity as they undertook the GED program. Additionally, the article examines these factors for their potential to influence the participants' learning of mathematics. The study itself took into account the early mathematics education of the participants in order to explore relationships from their GED experiences to that of their prior experiences. It asks how the GED program impacts the identity of the students it is servicing in one First Nations community.

In this paper I have used the term First Nations to represent the students in my study because none of the participants identified as Inuit or Metis. I have used Aboriginal to include Metis and Inuit, and to denote peoples who are indigenous to North America. The term Indian is used as a legal construct.

\section{Background}

The failure of Eurocentric education to meet the needs of First Nations students (Battiste, 2002; McPherson \& Rabb, 2010), reveals the importance of addressing the impacts of cultural realities and their impacts on identity. Given the state of mathematics education for Aboriginal people as identified by First Nations Math Education (2009) and Fraser (2010), researchers have a responsibility to explore early life realities that may influence identity and impact learning of mathematics for some First Nations students.

One response to the failure of the Eurocentric education model at the First Nations community level has been to attempt remedial programs such as the GED. The GED program is an internationally recognized Grade 12 equivalency program with standardized testing protocols that leads to a diploma. A set of 5 examinations provides opportunities for students to demonstrate their academic credential equivalency. The students are expected to write the examinations for all subject areas over a two day period. The GED credentials and high 
exam failure rate are criticized by K12 academics (2012) and Kurens (2010) who contend that many colleges and universities do not recognize the GED tests in their entrance requirements. Additionally, Kurens argues that only 47.5 percent of New Yorkers that take the exams pass them. In this study, the community's Band Council had contracted the use of the GED to address the limited employment and educational opportunities for those community members who were not high school graduates.

My own position in relation to the study began with parents who trusted the education system that served me due to their own positive educational experiences. Even though I consider myself to be privileged in my upbringing and education, how I saw myself in the world held me back from the leap of faith required to visualize myself as a university student for a full 25 years after high school graduation. I have since earned an electrical engineering degree that provided me with a solid math background and I am currently working toward a $\mathrm{PhD}$ in education. I am married to an Ojibwa scholar who was brought up in a First Nations community and champions for Aboriginal causes in the academic world. I consider his leap of faith to be far greater than mine given the obstacles he overcame throughout his life. I have been active in the school communities that have addressed our children's math education for the past 13 years and have grappled with how their developing identities link to their self-perceptions as learners of mathematics. Additionally, I have taught adult First Nations students for three years as a non-Aboriginal educator teaching mathematics upgrading to students from remote First Nations communities, taught mathematics and electronics to adults and at-risk students for 11 years at Seneca College in Toronto and have both volunteered and been paid to tutor students struggling to discover their place in the mathematics world for 28 years.

\section{The needs of the communities through the lens of educators and academics}

The scholarship on First Nations adult education mathematics programs is sparse but the indicators are clear:

Statistics reveal that, in spite of some positive advances in adult education programs, more FN students complete non-university programs than university programs. A pressing need continues for more program development and learning theory in adult education. Where FN run programs do exist, they survive on unstable project funding. This often discourages program and curriculum development (Battiste, 2005, p. 9).

The literature on First Nations mathematics education has identified that the needs of First Nations students both in their communities and in urban areas is much the same as that for mainstream students. In 2009, the First Nations Math Education Banff International Research Station workshop brought mathematicians and math educators together with First Nations elders, teachers and representatives from various Bands to the Banff International Research Station. The group was organized to meet twice annually over a two year period. The meetings were meant to develop initiatives with which to promote opportunities for Aboriginal and First Nation students in the area of mathematics. The workshop participants agreed in principle that "the ultimate goal would be to provide all First Nations people with access to quality mathematics education, and be well-prepared to take advantage of it" (Banff International Research Station for Mathematical Innovation and Discovery, 2009, p. 6). The participants identified dissonance between the community and the schools, unwelcoming classrooms where student potential remained untapped and historical issues remained unrecognized, as well as a lack of accredited teachers able to teach full mathematics programs. Additionally, the workshop set out guidelines for a successful mathematics program in the context of First Nations education:

The mathematics curricula in First Nations schools must be up to the standards of curricula in other schools, and provide students with a realistic chance of being prepared to continue on to college if they so choose (and they should be strongly encouraged to so choose). This does not necessarily mean having, say, calculus available by the end of the twelfth grade, but students going on to college should be within one precalculus course of being ready to engage calculus....

It is important for students to understand that mathematics is an important element of their own living cultures, and not something that is solely "white people's knowledge," to put it bluntly (p. 6).

Western mathematics concepts have long been viewed as the 'only mathematics' capable of preparing students for college and university programs. Sterenberg (2013) argues that Indigenous mathematics is richly steeped in history, is regional in context, and that mathematics historically has been learned from place rather than to place. In this way, she contends that mathematics historically originated out of the land rather than brought to the land. Sterenberg suggests that "Western" mathematics differs from the mathematics of mathematicians and cites Aikenhead and Ogawa (2007), who argue that Western mathematics teaches to objectifying and materialistic concepts and in doing so, sidelines the indigenaity of its Indigenous learners. Sterenberg contends that each form of mathematics teaches to a different ontology. In addition, Meaney \& Evans (2012) argue that a commitment to 
transitioning mathematics back to the community must be part of a successful mathematics program for Indigenous learners to enhance identity factors of the community as a whole and that incorporating a historical context for mathematics programs can contribute to what is needed for this to occur. All learners of mathematics need to understand some of what was lost before they can comprehend that a loss has occurred. Such understanding is inclusive in that it acknowledges that its students are learning the mathematics of the dominant culture in order to feed the philosophical underpinnings of the culture's norms. In this way learning identity motives are explicit rather than implicit, opening up potential for an honest and open learning experience for all students of mathematics.

\section{Identity and Learning}

The scholarship that links identity to learning sets the stage for the depth of inquiry into this research. Wenger (1998) identifies learning as "an experience of identity ... [that] involves the ability to negotiate new meanings and become a new person" (pp. 215-221). Wenger argues that because learning is experiential, social, and transformative, identity is an educational resource, the accumulation of knowledge is not a means to an end but rather its role is to service the identity. Wenger highlights what he calls "a paradox of learning: if one needs an identity of participation in order to learn, yet needs to learn in order to acquire an identity of participation" (p. 277) and identifies this paradox as a fundamental definition of education. Haviland \& Kahlbaugh (1993) further suggest that identity is primarily constructed and driven by our emotions and made more complicated by the intersection of the differing aspects that make up who we are. The authors contend that emotions initiate how people view and move through their worlds and thus it can be said that emotions are the 'glue of identity' (Zembylas, 2003) in that they provide meaning with which to gauge experience. For the purposes of this study, I will define identity as the both the emotional responses that the participants bring to, and acquire within, their learning environments, and the negotiations necessary to participate in shifting identities. I have selected these aspects of identity firstly because of their critical involvement in the acquiring of mathematics skills (Woods, 2006). Secondly, the data in my study indicated a number of factors which contributed to the emotional lives of the participants, emotions that were both originally faced in their early education and then re-visited in the GED program and attached to seemingly unrelated incidents that impacted learning during the study itself. Finally, the structural component of the GED program requires consideration for its potential to generate and maintain a robust, interactive and participatory learning environment where student-learning identities can thrive.

The community that is the focus of this article itself is located on a large lake $200 \mathrm{~km}$ north of a provincial Ontario city. The 1,189 residents lay claim to the use of 3,940 hectares of lands held in reserve for Indians. Of this population, 400 are on-reserve residents (Aboriginal Affairs and Northern Development Canada, 2011). Eleven councillors plus the Chief makes up Band Council, which is responsible for the governance of the reserve under the legislative framework of the Federal Indian Act (1985).

\section{Methodology and Method}

I examined the scholarship on both ethnography and Indigenous Methodology (IM) (Kovach, 2010) as potential methodologies because I was interacting and observing with the participants in their environment in an attempt to deepen my understanding of the research. Ethnography seemed to respect and allow inclusion for all aspects of what IM proposes for a methodology. IM includes incorporating indigenous methods and epistemologies, situating culture and self, ethics, protocol, and meaning-making. As I was not limited by an ethnographical approach to the respectful research parameters of IM, I chose ethnography as my methodology. I incorporated observations and interviews because I felt that gaining a first-hand account from the students about their own learning would provide the depth of understanding that I was looking for. The community's Chief and Council selected the sample of students from community members who were interested in obtaining GED credentials. These students became the participants for my study after all Research Ethics Board protocols were followed. None of the participants were high school graduates, all were over the age of 21, and status Indians as defined by The Indian Act (1985). All of the participants resided in the First Nations community and as such, were able to provide information on the research topic. Concurrent to the interview process was my work with the participants in a support capacity for the development of their mathematical understanding toward their GED exam, which was scheduled for $31 / 2$ months after the program began.

Several semi-structured interviews focused on pre-defined, open-ended questions. Each interview lasted approximately 30 minutes and the location was mutually determined. The interview questions are detailed in Appendix A, and were developed upon review of the literature, and in conjunction with the recollections and feelings of the participants in regards to the prior learning of their mathematics. Elaboration was encouraged in a conversational exchange with the open-ended interview questions. The social setting of the interview was documented and considered in the interpretation of the data. Audio-tapes were transcribed and coded. 


\subsection{Coding}

When the interviews were transcribed and member checks completed, analysis of data using coding for common themes commenced. Struggles with identity developed as the major theme from the participant interviews about their past experiences and from the on-going observations and communications from the GED program itself. I coded the data using index cards to search for common themes. Consistency was adhered to throughout the collection process (Morse \& Richards, 2010). Data analysis was shaped by my experiences of working with the students as well as the reading of the literature.

As I had established a good rapport with all of the participants through their intense tutoring and teaching sessions, and had many years to gain a comprehensive understanding of their lived culture, prolonged engagement was corroborated (Lincon \& Guba, 1985, p. 301). Triangulation through providing member checks, opportunities for verification of the interviews of transcripts and opportunities to review the full draft of the paper took place (Lincon \& Guba, 1985).

Detailed notes were kept for all interviews where permission to audio-tape was denied. Five participants expressed discomfort with being audiotaped. I did not ask them for further explanation because I felt they needed to know that I accepted their contribution on their terms.

\section{Results}

The analysis of the data highlighted one major identity related theme that principally emerged from cultural incongruences with the GED experience. The importance of early life experiences in shaping personal attitudes towards mathematical ability impacted the participants' view of themselves as students, both in their formative education and into their adult learning. Disconnects which seemed to exist between the community and the participants' early education system emerged with symptoms such as bullying, and homesickness when students left their communities to attend high school, were all cited by the participants as factors that influenced their early math education.

\subsection{Early Life Experiences}

The interviews revealed that early life experiences dramatically affected the participants' rapport with mathematics. Trust issues, including trust in their own abilities became the link between their experiences and their learning trajectory. Positive role models seemed to help motivate students while bullying resulted in attrition and struggles with self-images that influenced learning in general. Diagnosis of learning difficulties that seemed to arise from bullying and being given repetitive work likely further interfered with student identity and issues of trust. Homesickness and cultural differences away from home meant that student emotional health needs were compromised. Residential school syndrome (Chrisjohn, 1997) further complicated identity issues and deepened divisions of trust when two participants explained that their parents who were residential school survivors, did not trust the education they were receiving. Chrisjohn describes residential schooling as 'the 'education' delivered, time and again, (which) did not have as its goal the broadening of intellectual horizons, but rather the inculcation of the images Europeans carried of themselves and of the oppressed into the oppressed." (p. 151)

Absenteeism also played a role in truncating educational opportunities. Hunting, overcrowded housing resulting in lack of sleep, bullying, being given work that was too easy and deaths in the family are among the main reasons given for students being absent. Cara, who was brought up by her father, was open and prided herself in her honesty and her ability to connect with her educators. She returned to the community school for grade four and was transferred to the high school at the end of grade seven because of her age. She attended a transitions program in her high school from grades nine to eleven. Cara failed grade one because she did not attend, and without proper remediation, this deficiency appears to have stifled her future learning. She remembers returning from the provincial system to her community school in grade four:

I was looking forward to math in elementary school. But they kept giving us the same work over and over again. They would give us the same worksheets. I felt smart at first until I finally figured out that they were handing us the same sheet. I felt like I was being laughed at, being played with . . like with my emotions, making me think I can do this at the blink of an eye but meanwhile it was the same paper.

Cara was one of two participants who discussed bullying inside the classroom as a major influence on her school experience.

When I came down here (to go to school in her community), I was the smartest one and not bragging or anything but I knew more than what they knew and the kids didn't like that. They dragged me down. They called me smart ass, teacher's pet. They picked on me, picked on me. The kids came after me for help. I got bullied and I didn't want to go to school so I didn't for a while. I took a year off. I knew more because I came from town. 
Another encounter that impacted negatively on some students, including Cara, was the transfer to high school, and the feelings of insecurity and inadequacy that this evoked. Michael was a personable young man whose attendance was more of an issue than it was for any of the other participants. He attended all of his elementary years in the community school. Michael spoke of his experience of transferring schools:

I was transferred into high school because of my height and age. I was 13. The boarding out was alright but it would have been better if I had my mother there to get me up and stuff like that. Coming from a reserve into a big city was basically culture shock. I didn't catch on right away in high school. I thought I was doing good but then when they tested me I was at a grade 6 level. It was messed up.

At the age of 15, Cara, whose mother died when she was a young girl, was in grade seven when she transferred directly to high school without grade eight:

I was sent for the transitional program. I passed grade 9 and went there until grade 11. I did not feel comfortable there.

Cara continued with memories from the doctor who tested the entry Aboriginal students in her high school:

In grade 9 there was a doctor that goes to all the schools and checks the Aboriginals because a lot of Aboriginals have problems when they come from their communities. He gave me a test with blocks and ducks and you had to see how fast you could do it. I felt like a Chimpanzee. The questions were common sense. I was told that it takes me a long time to comprehend things and that I understand better when people show me, not tell me how to do things. Maybe it is hard for me when people talk too fast.

During the interview process I asked Cara if she agreed with the doctor's diagnosis. She replied:

Yes, I think he is right.

As a researcher, I found Cara's mathematical experiences to be poignant because she had clearly gone from a bright capable student to one with diagnosed learning issues within five years. I worked with her at her kitchen table over lunch and after school to accommodate her perceived need for one-on-one tutoring and to work outside of the classroom but concluded that her early educational experiences continued to adversely affect how she perceived she needed to learn mathematics.

Michael talked about not being taught enough in the schools:

I can remember teachers teaching me who were from (this community). Maybe that is all the math they were taught in residential schools so that is all they taught us.

\subsection{Culture and Traditions}

The participants were asked about their perceptions of traditional and cultural associations with mathematics. When interviewing the participants, I distinguished "culture" from "traditions" and gave each participant the opportunity to voice whether they thought either or both held a place in the learning of mathematics for them. I defined culture as the contemporary values and interactions that defined their communities, as they were being experienced by them, in their present lives. I defined traditions as ceremonies and practices that have been passed down for generations by their ancestors.

All of the participants were asked how important they felt it was to incorporate traditions and culture inside of the teaching of mathematics, particularly as examples for problem sets. Five participants felt that teaching of traditions and culture would enhance student learning of mathematics to varying degrees and six participants felt there was no place for traditions and culture in mathematics teaching.

Kaylee was the most proactive student in the GED program which was interesting because she entered the program with a solid grade 5 level of mathematics. She experienced all of her elementary education at the community school. She was pushy with her learning, demanding attention when she needed it. During interviews I advised more than one student to watch Kaylee's behaviour closely because she had all the makings of becoming an excellent student. Suzie attended the community school for her entire elementary education and was evaluated with grade 5 math skills at best. She attended grade nine briefly but dropped out when she realized that she did not understand any of the mathematics. Suzie and Kaylee saw no place for Aboriginal ways of knowing or cultural components for learning mathematics but both indicated that they like to learn traditions in their education. David is a proud young man with a young family whom he looks after. He was the third strongest participant in the mathematics portion of the program. David switched schools four times in his elementary education and attended the community school from JK to grade 3 then again for grades 5 and 6 . David admitted that some people might like to see traditions in math but he indicated that he did not want them. Maureen was quiet but resolute. A residential school survivor, Maureen displayed confidence, dedication and a 
genuine love of math in her gentle demeanour. She attended a residential school from JK to grade five but skipped grade three, six and eight to live in the bush. She claims to have not learned in the residential school. She attended a city school for grade seven, then attended grades nine, 10 and 11 in a city school.

Maureen helped other students in the class with the concepts and procedures and was well attended throughout the entire program. She passed the exam easily. Maureen suggested that traditions are not relevant for math but they are for language.

Tina spoke of traditions,

I think it is important to see it in math problems. It would make it easier to relate to the problems.

Elizabeth did not ask questions in class and was very conscious about how others perceived her math skills. Her tumultuous upbringing was fraught with issues of violence and substance abuse. Elizabeth was confused by the question of culture and traditions.

Math is math. There is no Native math. There is just math.

Cara agreed,

It doesn't really matter if a problem says two little white people or two little Indians. It doesn't really matter to learn.

Anne continued expressing frustration with the accuracy of what she is learning in her traditions.

Sometimes people learn and then they get upset because that really isn't the way it was. It is better to learn it in my own community because it is more accurate. If it is taught at school I get frustrated because it isn't taught right and then I refuse to do the work. It gets us mad when a white person tries to teach that stuff because what the hell do they know? It should be like a Native. But then they get offered money and that isn't really what it is all about you know?

Anne is the mother of several children who live with her in the community. She attended the community school for JK and SK only. She attended four elementary schools and two secondary schools in total. She has a robust personality and a keen sense of humour. Anne acknowledged:

Dilico used to come into the schools to teach traditional stuff but there would be maybe one Indian and the rest were white. I like it when Indians teach traditions.

Sarah is the owner of a strong, solid identity, perhaps the strongest of the group. Sarah made a point of giving me a moose roast in a display of generosity which defined her nature. She helped other participants throughout the program. Sarah exhibited wisdom beyond her years in many of our discussions as we travelled to and from the city together.

Sarah reflected on traditional teachings and cultural inclusion in mathematics,

I would use tepees with wood stoves. I find it is easier to learn, easier to understand. When we are interested, we are having fun and it isn't really work. . . we can relate more.

She indicated that helping someone in your family to solve a problem is more interesting than helping someone you don't know.

Cultural components are important because they help you learn better and they help you be a better all-round person.

\subsection{GED Experiences}

As a tutor/teacher with experience working with older students, I decided from the outset that it was up to me to set up a learning environment based on mutual trust. On the first day I took some time to offer up a synopsis of my own journey through life, which included its struggles and solutions that I found worked for my family in our educational endeavours.

With the guidance of the Coordinator and the thoroughness of the Director of the program, the classroom was provided with the supplies that were needed to teach and learn. Babysitting was paid for where needed. The participants were paid for each session they attended. The class quickly became a unit that was strong, tight and motivating for everyone. Nursing at the college level, paramedics and starting up a restaurant in the community were all included in participant goals with nursing predominating. Cracks in the dedicated and consistent work habits of most of the participants began to emerge shortly before I was instructed by the director to begin teaching directly to old GED exams, 3 months into the program. Attendance was becoming an issue for the first time. I set up a five day marathon where the students would write the pre-tests, we would take them up and they would immediately write them again. 
Medical appointments, hunting season and child-care issues resulted in attendance issues throughout the program but attendance overall was relatively stable prior to the five day marathon.

The five days were well attended by three students and somewhat attended by another two. Kaylee, who had expressed frustration with the Coordinator on several occasions, did not attend because the Coordinator attempted to cancel the first day of the marathon citing weather conditions. Michael expressed frustrations that the Coordinator was treating him like "a child." Elizabeth later explained that she did not attend because her weekends are her own. Suzie went to the city to seek medical attention for her child. David stayed home to look after his children. We worked through four exams twice. Although all of the marks were well below passing on the first attempt, all exams were above passing on the second.

In the days following our next regular session, all students who did not attend the five days quit attending classes. Elizabeth, Kaylee and Suzie did not write the exam. Michael wrote but talked with Anne throughout much of the exam time until the GED examiner told them if they continued, they would have to leave. Cara informed me later that she did not do any calculations. She guessed at most of the answers which were largely multiple-choice. When given a second opportunity, she consumed large amounts of alcohol the night before our last studying session.

\subsection{Context}

It became increasingly obvious to me that many of the participants had developed sophisticated methods for "spitting in the eye" of my belief in their abilities to pass the exams based on the math they had learned in the program. They had been down this road before and setting up familiar conditions of downfall was easy compared to being asked to believe in their ability to overcome them. Three of the eleven participants passed the GED mathematics exam. This data corresponded with K12 academics (2012) and Kurens (2010) who noted that most of the students who wrote the GED exams did not pass them.

\section{Discussion}

Battiste (2005) expresses concerns that students are not being encouraged to complete university programs was evidenced in this study by the very nature of the equivalency of high school credentials through the GED program itself. None of the participants were opting to strive for acceptance into university at the commencement of the program although Sarah was seriously considering the possibility after we engaged in long discussions during our drive from the neighboring city to the community.

Identity issues seemed to establish the framework for the participants' descriptions of the aspects of their lives that brought them to the point of being a part of the GED program. Cara's emotional reaction to being bullied seemed to contribute to her decision not to attend school which may later have led to a diagnosis that pigeonholed her in her own mind for the duration of our time together. The reasons Cara sited for the bullying itself give evidence to Meaney \& Evans (2012) claim that good mathematics programs can be seen as alienating when they do not contribute to the community as a whole. Additionally, Cara's situation seems to comply with Foucault's 1973 and 1977 works which argue that professional bodies can and do make certain that the behaviour of children is identified in definitive ways. Cara recalls that she once thrived in a normal classroom but her belief in the doctor's diagnosis seems to be so predominant in her mind that she now questions her capabilities.

When the students opted out of the exams, they were avoiding failure in a system that was external to the lives they experienced in their community albeit that many, if not all believed that they were not only expected to be inside of, but were examples of failures inside of. This was evidenced by those that discounted cultural and traditional inclusiveness with mathematics learning and by those whose understanding of connections to the traditional ways offered by their ancestors was superficial and supported only by examples in word problems. One example of this was Sarah's attempt to relate the mathematics she was learning back to her traditional roots in order to create a fun and engaging learning experience. Sarah did, however, see incorporating her traditions as supportive in becoming "a better all-round person". Tina may have seen her traditions more as a tool to connect to the mathematics of another culture that is in the process of becoming hers rather than a source of profound belonging that contributed to the mathematics itself as envisioned by Aikenhead and Ogawa (2007). With many of the participants seeing little or no use for cultural or traditional inclusion, one might wonder if the assimilation process which began with the residential schools of many of the ancestors of the participants was reaching fruition.

Further, Cara's experience at 'being given the same work over and over again' also reflects on the quality of her early mathematics education and the quality of the teaching that took place within it. Cara's recollections are in line with the First Nations Math Education, (2009) results that claim that many teachers of First Nations students are not able to teach quality math programs. With $3 \frac{1}{2}$ months to learn eight years of mathematics programming, certainly the educators and elders at the Banff International workshop would agree that these students were not "well-prepared to take advantage" of the program (First Nations Math Education, 2009). 
If Wenger's (1998) claim that identity is an educational resource is valid, then this resource was compromised for the eight participants who did not pass the exam as was evidenced when only one student attempted the supplemental exam that was offered one month later. When the students were asked to stop learning concepts in favour of studying for the exams, their participation in their own learning was shut down. In the words of Wenger (1998), the information students procure must require a pathway to an identity of participation to be empowering. As the exams were non-negotiable, their inevitability rendered the information needed to study for them "alien, literal, fragmented, nonnegotiable" (p. 220). In the GED mathematics program that Sterenberg (2013) would argue was 'brought to the community', eight participants continually exhibited signs that they did not view themselves as students of mathematics, despite sharing career goals with me that required them to be and despite showing strong progress in their learning. This, in itself appeared to impede their ability to see themselves as being able to pass the GED mathematics exam and was further revealed by their deteriorating attendance and work habits as the set examination dates loomed.

My findings agreed with Zembylas (2003), in that emotions provide the glue for identity and that as such, they are fundamental to student learning. Many of the participants indicated that their emotional lives interfered with their learning. While tutoring the participants throughout the GED program, emotional difficulties such as the death of loved ones, relationship issues, parenting issues and even the incarceration of loved ones created emotional concerns that the students had difficulty moving beyond for the purposes of their studies. This occurred despite counseling sessions that were provided by the program Director to support these issues. In truth, it was difficult to distinguish the extent that the emotional triggers were the direct cause of learning detachment versus the justification the participants needed to avoid their own perceived ultimate failure to be successful in the program.

The GED program funded students for $31 / 2$ months to work through eight years of mathematics curriculum, a massive undertaking for any mathematics student. Given that most participants endured crisis situations while I was there, and that student self-perception of ability was centred around their performance during the exam, there is no doubt in my mind that they were set up for failure through the assessment criteria itself and that, as their tutor I helped to set that in motion. If these students were indeed measuring their own achievement by the standards of the dominant culture, three students were saved through the experience when they passed the exam. Two students talked and laughed throughout the exam, thus removing themselves from the possibility of 'perception of failure' during the last hours. Three students did not write the exam, thus engaging in a process of "spitting in the eye of a ruling ideology" that they had participated in when they were teenagers (McClaren, 2002, p. xxxiii). Clara admitted to guessing at the answers because she felt she was good at guessing, thus describing her self-perceptions in a similar light. The two remaining students wrote and did not pass the exam so walked away with a perception of failure that they did not have of themselves when they entered the program. Too much was asked of these hard working students in too short a period of time. Further, when I worked extensively with Cara after the first exam, she became the third student whose identity was altered by a perception of failure when she wrote and did not pass the second exam. Her decision to drink large amounts of alcohol before our last study time, may have been her attempt to 'spit in the eye' of my belief in her ability to pass the exam without guessing at the answers. Most of the students did not return for the supplemental examinations, likely due to the lack of funding needed to sustain the full supports that existed for the first $3 \frac{1}{2} 2$ months. This supports Battiste's 2005 claim that the temporary aspect of program funding is detrimental to the ability of programs to meet with success. The GED program did not meet The First Nations Math Education, (2009) criteria for a quality mathematics education program based on its failure to provide the time necessary to upgrade students who are working at a grade 4 or 5 level of mathematics. The examination criteria that all exams must be written over the same two day period with all of the assessment weight contingent upon the passing of the exams also excluded it from the quality programming that was outlined in The First Nations Math Education, (2009).

My data indicated that there are complex layers of research that must take place if we wish to unravel the social and political network that is driving First Nations students away from the pursuit of mathematics. McPherson and Rabb (2010) and Adams (2010) argue that at the present time, First Nations people are without an identity of their own, and that this contributes to difficulties with learning.The participants, however, were keenly aware of niches within the community where they might provide a service to meet immediate needs lending evidence that linking their learning back to community was clearly important for the participants as suggested by Meaney \& Evans (2012).

Wenger's (1998) requirement for participation and Sterenberg's (2013) call for inclusion were necessary for the participants to agree to exchange aspects of their identities in favour of a more liberating belonging in the learning of mathematics and this participation needed to exist throughout their entire learning process. For eight of the participants in this study, the inevitability of the exams removed all likelihood of this prospect. 


\section{Conclusion}

In this paper, I have delineated the core problems with the delivery of the GED program to be steeped in identity. This paper has attempted to outline some of the circumstances that affect student identity for mathematics learners in one First Nations community. The data indicates that the GED program opposes cultural inclusion, in that its mode of delivery is one directional. The mathematics from the GED program was clearly brought to the community and was lacking any reciprocal component which might have encouraged more inclusion as discussed by Meaney \& Evans (2012). Quality programming was evident for the students until the prospect of studying for the exams themselves became imminent. At that point the participants in the study developed creative ways to preserve their existing relationship as non-learners of mathematics including "spitting in the eye of a ruling ideology" (McClaren, 2002, p. xxxiii). The program lost its ability to service the identity of the participants and was thus rendered a means to an end (Wenger, 1998, p. 215). Additionally this study supported the scholarship that positions learning mathematics within the community as requiring ongoing negotiation and participation on the part of learners, and program delivery in an open, rich learning environment which links effectively and solidly back to community.

\section{Acknowledgements}

I would like to acknowledge my supervisor Wayne Melville for his editing of this paper, the sharing of his resources, and his ability to motivate my writing.

\section{Appendix A}

\section{Interview Questions}

1. Which elementary school did you attend and in what years?

2. Which secondary school did you attend and in what years?

3. Describe your mathematical experiences in your elementary years.

4. Describe your mathematical experiences in your secondary school years.

5. Describe the support you received, both at home and at school, for your mathematics education.

6. What did you feel about the mathematics that you were taught in school?

7. Could you comment on the relevance of the mathematics you learnt at school to your everyday life?

8. Why are you pursuing the GED certification?

9. How best do you believe you learn mathematics?

10. How important is it for you to understand mathematical concepts in order to apply the methods you are taught?

11. How important is it to you that your cultural or traditional understandings be reflected in the mathematics you are learning?

\section{References}

Aboriginal Affairs and Northern Development Canada. (2011). Retrieved on July 14, 2012 from: http://pse5esd5.aincinac.gc.ca/fnp/Main/Search/FNMain.aspx?BAND_NUMBER=188\&lang=eng

Aikenhead, G., \& Ogawa, M. (2007). Indigenous knowledge and science revisited. Cultural Studies of Science Education, 2, 539-620. http://dx.doi.org/10.1007/s11422-007-9067-8

Alston-O'Connor, E. (2010). The Sixties Scoop: Implications for social workers and social work education. Critical Social Work, 11(3), 53-61.

Anderson, R. (2007). Being a mathematics learner: Four faces of identity.The Mathematics Educator, 17(1), 7-14.

Battiste, M. (2005). State of First Nations Learning. Prepared for Canadian Council on Learning. Retrieved on June 12, 2013 from: http://www.ccl-cca.ca/pdfs/AbLKC/StateOfFirstNationsLearning.pdf

Battiste, M. (2002). Indigenous knowledge and pedagogy in First Nations education. A literature review with recommendations. Retrieved on December 12, 2012 from: http://www.afn.ca/uploads/files/education/24._2002_oct_marie_battiste_indigenousknowledgeandpedagogy _lit_review_for_min_working_group.pdf.

Chrisjohn, R. (1997). The Circle Game: Rethinking the Indian Residential School Experience in Canada. Penticton, BC: Theytus Books. 
Criticism of GED K12 Academics. (2013). K12 Academics. N.p., n.d. Retrieved on February 28, 2012 from: http://www.k12academics.com/academic-testing/ged-testing/criticism-ged.

Dunn, T. K. (2004). Enhancing mathematics teaching for at-risk students: influences of a teaching experience in alternative high school. Journal of Instructional Psychology, from http://findarticles.com/p/articles/mi_m0FCG/is_1_31/ai_n6073186/.

Expert Panel of Student Success in Ontario. Leading math success: Mathematical literacy grade 7-12: A Report of the expert panel of student success in Ontario, (2004). Toronto, ON: Queen's Printer for Ontario.

First Nations Math Education. (2009). Banff International Research Station for Mathematical Innovation and Discovery. Retrievedon July 14, 2011 from: http://www.birs.ca/events/2009/5-day-workshops/09w5078.

Foucault, M. (1977). Discipline and punish: The birth of the prison. New York: Pantheon.

Foucault, M. (1973). The birth of the clinic: An archaeology of medical perception. New York: Vintage Books.

Fraser, S. (2010). Opening Statement to the Standing Senate Committee on Aboriginal Peoples, Indian and Northern Affairs Canada-Education Program and Post-Secondary Student Support. Retrieved August 10, 2010 from: http://www.oag-bvg.gc.ca/internet/English/oss_20100512_e_33879.html.

Haviland, J. M., \& Kahlbaugh, P. (1993). Emotion and identity, in: M. Lewis \& J. M. Haviland (Eds) Handbook of Emotions (pp. 327-339) (New York, The Guilford Press).

Indian, A. (1985). Bill C31. Retrieved on August 18, 2012 from http://www.johnco.com/nativel/bill_c31.html.

Kovach, M. (2009). Indigenous Methodologies, Toronto: University of Toronto Press.

Kurens, J. (2010). Poor Preparation, Confusion Lead Many to Fail GED Test. Gotham Gazette. Retrieved on Feb. 28, 2012 from: http://old.gothamgazette.com/article/education/20100518/6/3270\#sthash.nbwzjxwl.dpuf

Lifelong Earning: Research Skills. (2010). Retrieved on December 12, 2011 from http://sydney.edu.au/science/uniserve_science/projects/skills/jantrial/research.htm.

Lincon, Y. S., \& Guba, E. G. (1985). Naturalistic Inquiry. Beverly Hills: Sage Publications, Inc.

Ma, L. (1999). Knowing and Teaching Elementary Mathematics, Mahwah, NJ: Lawrence Erlbaum Associates.

McPherson, D., \& Rabb, D. (2011). IndianFrom the Inside. Jefferson, N.C.: McFarland and Company Inc.

Meaney, T., \& Evans, D. (2013). What is the responsibility of mathematics education to the indigenous students that it serves? Educational Studies in Mathematics, 82(3), 481-496. Retrieved from http://ezproxy.lakeheadu.ca/login?url=http://search.proquest.com/docview/1347460067?accountid=11956

Morse, J. M., \& Richards, L. (2010). Read Me First for a User's Guide to Qualitative Methods. Thousand Oaks, CA.: Sage Publishing.

Shields, T. (2012). Achievement Issues for Aboriginal Students in Mathematics Programs. Saarbrücken, Germany: Lambert Academic Publishing.

Sterenberg, G. (2013). Considering Indigenous Knowledges and Mathematics Curriculum. Canadian Journal of $\begin{array}{lllll}\text { Science, Mathematics and Technology } & \text { Education, }\end{array}$ http://dx.doi.org/10.1080/14926156.2013.758325

Wenger, E. (2003). Communities of Practice Learning, Meaning, and Identity. Capetown, S.A.: Cambridge University Press.

Woods, D. (2006). Coping With Math Anxiety: A Workshop for Students. Retrieved on February 12, 2013 from: http://www.austincc.edu/math/documents/Coping_With_Math_Anxiety.pdf

Zembylas, M. (2003). Emotions and Teacher Identity: A poststructural perspective. Michigan State University, 9(3), 213-238.

\section{(c) EY}

This work is licensed under a Creative Commons Attribution 3.0 License. 